\title{
Veríssimo, Che Guevara e o discurso do consumo
}

\author{
João Anzanello Carrascoza ${ }^{1}$
}

Resumo: Retextualizar, conceito de Bettetini (1996), é a operação de mobilizar texto de um certo domínio, o literário, por exemplo, para o científico. Com o objetivo de discutir questões tradicionalmente centrais, ou emergentes, relativas ao consumo de bens materiais e/ou simbólicos, temos desenvolvido pesquisas sobre o discurso publicitário por meio de retextualizações de obras de ficção contemporâneas. Dessa vez, vamos nos valer do conto $O$ pôster, de Luis Fernando Veríssimo, para investigar algumas das estratégias discursivas mais exploradas pela publicidade, apoiando-nos em estudos da retórica publicitária e em pressupostos teóricos da Análise de Discurso de linha francesa.

Palavras-Chave: Consumo. Literatura. Publicidade.

Abstract: To re-textualise Bettetini's concept (1996), is the operation which consists in mobilising a text of a certain domain, the literary one, for instance, towards the scientific domain. Our objective is to discuss traditionally central or emergent questions, which are relative to the consumption of material or/and symbolic goods, therefore we have been developing researches on the discourse of advertising by means of the re-textualisations of contemporary works of fiction. This time, we will make use of the tale $O$ pôster [The poster], by Luis Fernando Verissimo, in order to investigate some of the discursive strategies, which are more explored by advertising, basing ourselves on studies of the rhetoric of advertising and on theoretical presuppositions of the French Discourse Analysis.

Keywords: Consumption. Literature. Advertising.

1 Doutor em Ciências da Comunicação pela Universidade de São Paulo. Docente da Universidade de São Paulo e do Programa de Pós-Graduação em Comunicação e Práticas de Consumo da Escola Superior de Propaganda e Marketing. E-mail: jcarrascoza@espm.br 


\section{Consumo, logo me comunico}

Nas últimas décadas, o consumo se tornou um objeto de estudo significativo em diversos campos do conhecimento, como a antropologia, a sociologia, a economia e a comunicação social, entre outros. A relevância da mídia no mundo contemporâneo ampliou e intensificou, além de tornar mais complexo, os fluxos comunicacionais que difundem numerosos tipos de discursos do consumo.

Tais discursos se materializam, mais explicitamente, por meio de mensagens publicitárias que estimulam a aquisição de bens materiais e simbólicos, ou de forma mais indireta, por meio de músicas, livros, filmes de longa metragem, telenovelas, talk shows, seriados de tevê, enfim, um enorme rede discursiva cujos fios ideológicos expressam as mais distintas práticas de consumo em nossa sociedade.

Canclini (2010, p. 29) compreende que o indivíduo ascende à cidadania mais pelo "consumo privado de bens e dos meios de comunicação do que pelas regras abstratas da democracia ou pela participação coletiva em espaços públicos”. O consumo é, pois, pessoal, material e midiático - lugar onde o simbólico se espraia de forma mais massiva.

Por meio daquilo que consumimos, estamos nos comunicando, produzindo efeitos de sentido sobre nós mesmos e sobre os outros - porque os outros são aqueles que também (ou, principalmente) nos leem.

Assim, se o simples ato de consumirmos algo materializa, como um texto, um discurso que enunciamos, para capturar o seu sentido, é preciso, como afirma Brandão (2012, p. 22-23), compreender "o contexto sócio-histórico-ideológico que envolve os interlocutores, o lugar de onde falam, a imagem que fazem de si, do outro e do objeto de que estão tratando".

Martín-Barbero (2009, p.293) propõe uma relação seminal entre a leitura e o consumo:

Se entendermos por leitura "a atividade por meio da qual os significados são organizados num sentido", resulta que na leitura - como no consumo - não existe apenas reprodução, mas também produção, uma produção que questiona a centralidade atribuída ao texto-rei e à mensagem entendida como lugar da verdade que circularia na comunicação [1]. 
É por isso que o consumo se apresenta como um "lugar de valor cognitivo, útil para pensar e atuar de forma significativa e renovadoramente, na vida social", conforme aponta Canclini (2010, p. 72).

Se consumindo estamos nos manifestando discursivamente, então podemos, pelo nosso consumo, contrapor, provocar, protestar, entrar em junção ou disjunção com os outros.

A frase de Che Guevara "hay que endurecer sin perder la ternura jamás”, encimada por sua foto histórica, tornou-se guia de conduta de militantes de esquerda mundo afora. Mas, uma vez dissociada de seu contexto original, estampada na camiseta vestida por um jovem burguês que se dirige ao um show de rock, o que está nos dizendo? Ou mais precisamente: o que nos diz esse jovem consumindo tal "simbologia" que ele leva no peito? E o que consumimos nós ao ver tal "enunciado" no corpo desse jovem - enunciado que, em seu corpo, ganha outros efeitos de sentido?

A propósito, Adilson Citelli (2008, p. 8), comentando uma campanha da palha de aço Bom Bril, cujo slogan dizia "hay que endurecer con la gordura sin perder la ternura con las manos jamás!”, mencionava essa "apropriação indébita do capital revolucionário alheio, mas de larga eficiência mercadológica e vastíssimo sucesso entre as várias classes sociais". E, depois de pensar no caminho "tortuoso" pelo qual a imagem do Che, partindo inicialmente da Sierra Maestra, foi desembocar, como adorno, "em camisetas vendidas em butiques de luxo e biquínis desfilados por estrelada modelo na badalada São Paulo Fashion Week", Citelli (2008, p.8-9) se perguntava onde teria ido parar o ethos, o caráter, a singularidade do "charmoso" combatente, uma vez empreendida essa apropriação de sua imagem pela publicidade.

Pois é por meio desse exemplo, a célebre imagem de Che Guevara, que pretendemos empreender uma reflexão sobre o deslizamento dos sentidos - sempre em movimento no espaço social -, a criação publicitária e seu discurso do consumo, a partir do conto $O$ pôster, de Luis Fernando Veríssimo, que traz como elemento nuclear de sua trama justamente a foto do guerrilheiro estampada na sala de estar de um apartamento de classe média. 
Assim, procedemos a uma retextualização, conforme Bettetini (1996) deslocando um texto do domínio literário para o domínio científico, e extraindo de seu enredo pontos de conexão com a discussão que propomos - de caráter ensaístico, por evocar, segundo Adorno (2003) em O ensaio como forma, uma certa "liberdade de espírito".

\section{Veríssimo: um escritor vindo da publicidade}

Luis Fernando Veríssimo é reconhecidamente um "criador" de tipos marcantes da literatura brasileira contemporânea. $O$ analista de Bagé, a velhinha de Taubaté, Ed Mort e Dora Avante são alguns de seus personagens de maior sucesso, explorados largamente em suas inumeráveis crônicas.

Autor de uma produção volumosa, que soma dezenas de livros de histórias curtas (crônicas e contos) e longas (romances e relatos de viagens), além de cartuns e quadrinhos, Veríssimo escreve predominantemente textos de humor, em especial sátiras de costumes do homem brasileiro, que são, como tão bem definidas pelo título de uma de suas obras, "comédias da vida privada". O universo da classe média nacional é, por consequência, tematizado, se não obsessivamente, com freqüência em muitas de suas obras, como nas Aventuras da Família Brasil.

Entre várias atividades que exerceu profissionalmente, Verissimo foi publicitário - alguns de seus textos, como é o caso de $O$ pôster, revelam, ainda que de modo implícito, seu sólido conhecimento sobre as estratégias retóricas utilizadas em discursos persuasivos, ou fechados, como os nomeou Umberto Eco em Obra Aberta (1981) - aqueles cujo significante está limitado a um significado -, embora nem todos propriamente tratem da publicidade.

Mas há muitos textos, como "O desafio", nos quais Veríssimo aborda de forma direta - e divertida - particularidades profissionais do universo da propaganda. Nesta crônica, um publicitário morre "e, como era da área de atendimento e mau para o pessoal da criação", vai para o Inferno. $\mathrm{O}$ autor apresenta, já na primeira linha o conflito histórico que há entre essas duas áreas das agência de propaganda (atendimento e criação). Pois bem: o Diabo, ao saber da chegada do 
publicitário, resolve lhe fazer uma proposta, melhorar a imagem do inferno, dandolhe em contrapartida regalias atraentes, como ar-condicionado:

O publicitário topou. Era um desafio. E as regalias eram atraentes. Quis saber algumas coisas que diziam do Inferno e que mais irritavam o Diabo.

- Bem. Dizem que aqui todos os cozinheiros são ingleses, todos os garçons são italianos, todos os motoristas de taxi são franceses e todos os humoristas são alemães.

$-\mathrm{E}$ é verdade?

- É.

- Hmmm - disse o publicitário. - Uma das técnicas que podemos usar é a de transformar desvantagem em vantagem. Pegar a coisa pelo outro lado (VERISSIMO, 1985, p. 93-94).

Essa técnica, de transformar a desvantagem em vantagem, é, lato sensu, a essência da atividade publicitária, uma vez que todo produto ou serviço apresenta vantagens, realçadas pela publicidade, e desvantagens, quase sempre omitidas por ela. No stricto sensu, podemos associá-la a vários recursos suasórios utilizados pelo discurso publicitário, como os lugares de qualidade e a valorização do inferior (CARRASCOZA, 2004). Exemplo do primeiro recurso - lugar de qualidade - é a campanha da pequena rede de postos de gasolina São Paulo que, não podendo se comparar com redes formadas por centenas de unidades como a Shell, apresenta-se como "a maior rede em simpatia". Já a célebre campanha da locadora de automóveis Avis, que a posicionava como a segunda do mercado, nos Estados Unidos na década de 1960, e a do SBT - Sistema Brasileiro de Televisão, dos anos 1980, cujo slogan era "liderança absoluta do segundo lugar", são exemplos clássicos da valorização do inferior. Caso de sucesso mais recente, que se vale desse recurso, é a campanha "Pode ser Pepsi?”, na qual se insinua que o consumidor pede primeiramente o principal concorrente desse refrigerante, Coca-Cola, mas o vendedor diz que não tem e oferece Pepsi, que é aceita com satisfação.

Nessa crônica de Veríssimo, o publicitário, por meio da técnica de tornar a desvantagem vantagem, neutraliza as características negativas associadas aos ingleses, italianos, franceses e alemães e, assim, convence o Diabo que deseja imediatamente começar a campanha para mudar a imagem do Inferno. 
Mas, antes, o publicitário quer saber o valor da "verba". O Diabo, então, manda chamar o gerente financeiro do Inferno e afirma que a economia lá é dirigida por brasileiros. A afirmação, curiosamente, faz o publicitário desistir de enfrentar o desafio e obter as tais regalias: "me devolve pra grelha", ele diz, finalizando a história - o que revela, ironicamente, que não há como mudar a imagem de certos "produtos", sinalizando o "poder" relativo do discurso publicitário.

O escritor nos mostra, com esse exemplo ficcional, seu modo de ver a cultura contemporânea, além das virtudes e das limitações da publicidade.

Vejamos, então, como, a partir do conto $O$ pôster, podemos investigar que os dizeres não são propriedade particular, mas significam pela história e pela língua, conforme a situação discursiva.

\section{A memória discursiva e os dizeres publicitários}

O pôster abre o livro Os últimos quartetos de Beethoven e outros contos. Seu enredo se restringe à noite do jantar que será dado por um casal, João e Maria, na faixa de 30 anos, em seu "pequeno mas bem decorado apartamento", ao novo chefe do marido, André. Este vai promover, entre alguns candidatos, aquele que ocupará a vaga de Valtinho, um funcionário que morreu. Para fazer a sua escolha, ele mesmo se convidou para jantar na casa de cada um, começando por João que pede todo o empenho de Maria na cozinha para persuadir o chefe de que ele é quem merece a vaga: "Nossa renda pode duplicar. Vamos poder trocar de apartamento. Viajar para a Europa nas férias" (VERISSIMO, 2013, p. 14).

Enquanto bota ordem no apartamento um pouco antes de receber André, João se põe diante do pôster emoldurado de Che Guevara na parede da sala. Hesitante, pergunta a Maria qual a opinião dela a respeito:

- O Che? O que que tem o pôster?

- Ele fica aí ou a gente esconde?

- Esconder por quê?

- Porque o André pode não entender. Pode ter uma impressão errada.

- Que impressão errada ele pode ter? Que nós somos um casal de revolucionários? (VERISSIMO, 2013, p. 12) 
Notamos claramente, nesse diálogo, a preocupação de João em relação à imagem do Che, pois todo consumo enseja pertencimento (CANCLINI, 2010) e, no caso dele, um pertencimento que não parece ser positivo para ser comunicado ao visitante, e que Maria não se intimida em verbalizar: "que nós somos um casal de revolucionários?".

O receio de João, implícito, associa-se ao fato de que o "comandante Che" lutou contra as fundações do mundo capitalista - mundo que rege as empresas e as relações de trabalho que envolvem chefe e subordinados (interessados em ascender profissional e financeiramente).

Para João, seria perigoso revelar, por meio desse seu consumo do signo do Che, que ele é contrário ao sistema ao qual André, como chefe de seção de uma empresa, de certa forma representa. Maria está ciente desse risco, por isso argumenta, a fim de acalmar o marido:

- (...) João, lembra daquele pôster de tourada que a tia Bela trouxe pra você da Espanha? Tinha seu nome como um dos toureiros. E ninguém pensou que você tivesse participado mesmo de uma tourada. O pôster do Che é a mesma coisa. Um pôster do Che na parede não significa nada. Um dia pode ter significado, mas... (VERISSIMO, 2013, p. 12).

Temos aí dois enunciados que nos fazem pensar nas implicações de entender o consumo como um discurso: 1) "um pôster do Che na parede não significa nada" e 2) "um dia pode ter significado, mas...

No primeiro deles, as noções de interdiscurso - o eixo da constituição do sentido, onde estão os dizeres já-ditos - e de intradiscurso - o eixo da formulação, daquilo que se está dizendo no momento, em dada condição - são fundamentais para a nossa discussão. Orlandi (2000, p. 33) nos lembra que todo dizer "se encontra na confluência dos dois eixos: o da memória (constituição) e o da atualidade (formulação)" - o que vale, também, para este dizer "um pôster do Che na parede não significa nada”.

Nas águas dos dizeres já-ditos (interdiscurso), um pôster do Che na parede de uma sala de estar assume certos sentidos - a admiração dos donos da casa por essa figura "revolucionária", por exemplo -, mas, no encontro com o que se está 
dizendo no momento (o intradiscurso), essas águas em choque e movimento, podem não significar mais isso, podem, como diz Maria, não significar nada, ou seja, nada que "lembre" a sua história. Maria, portanto, está contando com o "esquecimento ideológico" - pelo qual, inconscientemente, pensamos que somos a origem do que dizemos, e, que, assim, não acionamos, em nosso dizer, sentidos pré-existentes.

Esse esquecimento estruturante, como afirma Orlandi (2000, p. 35), "reflete o sonho adâmico: o de estar na inicial absoluta da linguagem, ser o primeiro homem, dizendo as primeiras palavras que significariam apenas e exatamente o que queremos". E se consubstancia no segundo enunciado da mulher de João, "Um dia pode ter significado, mas..." Ou seja, o que dizemos não é só nosso, porque as palavras significam pela história e pela língua - o que foi dito em outro lugar também significa em "nosso" dizer.

Tal constatação nos leva a duas forças que se tensionam em todo discurso, a paráfrase e a polissemia - intensamente exploradas pela linguagem publicitária. A paráfrase atua pela estabilização, quando no dizer se mantém algo já dizível, a memória, portanto. A polissemia opera rompendo a significação já dada, "produzindo movimentos que afetam os sujeitos e os sentidos na sua relação com a história e a língua" (ORLANDI, 2000, p. 37).

Toda a vez que dizemos algo - e o dizemos sempre com palavras já ditas -, movimentamos a "rede de filiação dos sentidos". Maria tenta convencer o marido a não se preocupar com o pôster, investindo na força parafrásica, naquilo que está sedimentado, com o seguinte argumento: "João, lembra daquele pôster de tourada que a tia Bela trouxe pra você da Espanha? Tinha seu nome como um dos toureiros. E ninguém pensou que você tivesse participado mesmo de uma tourada. O pôster do Che é a mesma coisa". Quer dizer: o nome de João no pôster de tourada e a imagem do Che no pôster na parede significam o mesmo, que não é "verdade" - que João não participou de uma tourada, que o casal não é fã do comandante "revolucionário".

No entanto, João sabe que o chefe pode se emaranhar na rede de filiação de sentidos, e, pelo vetor polissêmico da linguagem, o pôster do Che pode "readquirir" para ele o antigo significado, e o diz para Maria - levando o casal a 
continuar a discussão entre os sentidos cristalizados no discurso (paráfrase) e os novos, que irrompem (polissemia):

- Aí é que está. Um dia significou.

- E você tem vergonha do tempo em que significou?

- Não é isso. O importante é que o André vai pensar. Ele não tem como saber se o pôster não significa mais nada, e é apenas uma peça de decoração, ou ainda significa pra mim o que significou um dia. E neste caso, adeus vaga do Valtinho.

- Esse seu André não pode ser tão tapado assim. Ele sabe que a cara do Che aparece até em tambor de escola de samba. Até em camiseta da Narcisa Sei Lá o Quê. Hoje não é símbolo de nada, é moda. A garotada que usa a cara do Che na roupa nem sabe quem ele foi (VERISSIMO, 2013, p. 12-13).

Maria, como vemos, insiste no esquecimento ideológico, lembrando a João que o chefe "não pode ser tão tapado assim", ele sabe que os sentidos não se originam em nós, "são determinados pela maneira como nos inscrevemos na língua e na história e é por isto que significam e não pela nossa vontade" (ORLANDI, 2000, p. 35). Assim, André sabe que a cara do Che aparece em tudo quanto é lugar e "não é símbolo de nada”.

João, contudo, ainda desconfia, pois não tem certeza se o outro também pensa, como a mulher, que o pôster é só uma "moda":

\footnotetext{
- É, mas ainda acho arriscado deixar o Che aí. Pra que arriscar?

- Se é por isso, é melhor esconder esses livros de cima da mesa de centro também. O seu André pode não gostar.

- Por quê?

- Os livros são do Picasso e do Francis Bacon.

- E daí?

- Um comunista e um veado. E se ele examinar os nossos CDs? Muita

Mercedes Sosa. Que nós nunca mais ouvimos, mas estão aí (...)

(VERISSIMO, 2013, p.13).
}

Nesse trecho do diálogo do casal, expande-se, como novos exemplos - os livros de Picasso e Francis Bacon - a tensão entre os processos parafrásicos e polissêmicos que operam os discursos. Como o pôster do Che, que, para Maria, emoldurado na parede da sala de estar (no tambor da escola de samba, ou na camiseta da garotada) não significa "nada", pelo menos não significa que eles, dono da casa, sejam fãs de Guevara (o que poderia contar negativamente na avaliação de 
André), também os livros ali de "um comunista e um veado", não os faz, igualmente, militantes comunistas e defensores da causa gay (o que, na opinião de João, comprometeria sua imagem perante o chefe).

Essa discussão do casal, que busca, em última instância passar uma imagem positiva deles a André, a fim de que João ganhe a vaga, leva-nos a ressaltar um fator essencial às condições de produção do discurso: a antecipação.

Por esse mecanismo, o sujeito tenta fazer que seus argumentos produzam efeitos sobre o interlocutor, coloca-se no seu lugar "antes" de dizer o que tem a dizer, e o diz pensando no efeito que desejaria provocar no outro. Orlandi (2000, p. 39) nos diz que essa modulação, para o sujeito do discurso, varia "desde a previsão de um interlocutor que é seu cúmplice até aquele que, no outro extremo, ele prevê como adversário absoluto". É justamente nesse ponto, na amplitude do espectro da antecipação, que João e Maria divergem.

E o embate segue, por que saber o que o chefe pensa é fundamental para João ser bem avaliado e ganhar a vaga de Valtinho. Assim, com toda certeza, a vida do casal iria melhorar - e Maria teria algo contra isso, ele pergunta?

- Depende do que a gente sacrifica para melhorar de vida.

- E o que nós estamos sacrificando? Esconder o pôster do Che Guevara é sacrificar alguma coisa?

- De certa maneira é.

- Você mesma disse que o pôster do Che Guevara não significa mais nada.

- O pôster não significa nada. Esconder o pôster significa (VERISSIMO, 2013, p.14).

A ideia de ocultar o pôster - uma ação igualmente significativa - nos faz recordar que o discurso não é constituído apenas por aquilo o que é dito, mas também pelos não-ditos - o dizível e o silenciado são elementos fundantes da teoria da Análise de Discurso Francesa.

Manter o pôster do Che na sala pode ter, certamente, um significado, que talvez André não aprecie, mas não o ter nas paredes pode ser igualmente danoso. Os não-ditos no apartamento também "dizem" sobre seus moradores. Da mesma forma, para Maria, esconder o pôster, ainda que o chefe de João não sabia, é um ato (um enunciado) que significa algo para eles, casal - algo que não deviam desdizer, pois, assim, deixam (só discursivamente?) de ser quem são. 
O jogo entre ditos e não-ditos se manifesta outras vezes no embate entre marido e mulher, e especialmente, destacamos aqui, logo em seguida, quando João pede para Maria trocar o vestido e colocar "aquele com decote", ao que ela se indigna:

- Você quer que o seu André veja os meus seios?

- Não é isso, Maria. Lá vem você. Quero que você esteja bonita para recebêlo.

- Com os seios à mostra, como uma oferenda.

- Não. Com toda a sua beleza em evidência. Ele vem aqui para me conhecer melhor, para ver como é a minha vida fora da firma. Como é o meu mundo. E você é uma parte importante desse mundo (VERISSIMO, 2013, p.14-15).

E se André se entusiasmar com os seios dela, Maria pergunta. João fica em silêncio. Como enunciador, ele sabe que as formações discursivas revelam a formação ideológica - por exemplo, a beleza de sua mulher mostra o seu bom gosto, como marido, ao mesmo tempo que, sem o dizer, “diz” que ele é heterossexual. Esse, aliás, é um detalhe expressivo (Wood, 2011), que, no entanto, na progressão da história, não significará nada aos olhos de André, ao contrário do livro de Francis Bacon ("um veado", na expressão de João), que vai lhe dar uma "pista” sobre quem é o dono da casa, como veremos a seguir.

O interfone toca, André está chegando. João, então, corre e tira o pôster do Che e o entrega a Maria, junto com livros e CDs - que podem comprometê-los ante o julgamento do chefe -, pedindo a ela para esconder tudo.

Ao entrar no apartamento, André senta numa poltrona e pega um dos livros sobre a mesa do centro, que o casal se esqueceu de "recolher". Um livro (ou um dizer, para nós), que expressa algo sobre João, com quem ele dialoga:

- Epa. Francis Bacon. Esse é o cara. Vi uma exposição completíssima dele em Madri, não faz muito. Esse é craque. Ele e o Lucien Freud...

- Eu também gosto muito dos dois.

- Você mora sozinho aqui, João?

- Não, não. Eu... (VERISSIMO, 2013, p.16).

Nesse instante, Maria entra na sala. E, pelo que afirma o narrador, "André ergue-se da poltrona, visivelmente surpreso". Surpreso, entendemos, porque o fato de João gostar de Francis Bacon e também de Lucien Freud não significa, para o chefe, que ele "apenas" gosta da obras dos dois artistas, mas também do que eles eram... 
No entanto, outros dizeres afluem na conversa, o que leva André a persistir na sua "leitura" sobre o que os objetos na casa de João estão dizendo sobre ele.

- Você é casado mas não usa aliança...

- Andei fraturando esta mão e os dedos incharam. Tive que cortar a aliança. Isto já faz tempo, mas ainda não mandei consertar. A aliança.

- A falta de aliança pode dar um sinal errado...

- Pois é...

André sorri.

- A falta de uma aliança pode destruir um sonho... (VERISSIMO, 2013, p.17).

A história segue nessa tensão entre a estabilização dos sentidos (paráfrases) e a sua ruptura (polissemia). Quando Maria comenta que precisa "de um homem para abrir o vinho", André se apressa e afirma "é comigo". Mas, com dificuldade para abrir a garrafa, ele fere o dedo e vai ao banheiro lavar as mãos. Logo, retorna à sala e se junta novamente ao casal:

- Errei de porta - desculpa-se André. - Entrei no quarto de vocês. Vi que tem um pôster do Che Guevara em cima da cama. Igual a um que eu tenho em casa.

- É - diz João. - Nós estamos tentando decidir onde colocá-lo.

- Ali - diz André, indicando o lugar na parede onde o pôster estava (VERISSIMO, 2013, p.19).

Depois da inconstância de significação (do pôster do Che, do livro de Francis Bacon, da aliança etc.), nessa dada situação discursiva, que perfaz toda a história de Verissimo, os sentidos, por fim, se estabilizam. E não apenas porque André também tem um pôster do Che igual em sua casa (e, certamente, signifique o mesmo na interpretação de João e Maria), mas porque outro "enunciado" (um gesto) o comprova, quando todos se sentam à mesa para comer: João sente o joelho de André encostar no seu - e não afasta a perna. Entrou no "jogo de sentidos" do chefe sabe o que ele quer e está disposto ao "sacrifício". 


\section{Concluindo: o retrato na parede às vezes dói}

Uma vez tendo percorrido esse percurso cômico-literário (com Veríssimo) e analítico (com elementos da análise de discurso ante a produção de sentidos e o consumo de significados), obviamentealgumas interrogações nos inquietam, e são elas, de certa forma, a força motriz que faz o conhecimento acadêmico avançar.

Se o consumo é um tipo de discurso, pelo mecanismo de antecipação, o que um jovem ao usar a imagem do Che na camiseta - e que ele não sabe quem foi, como afirma o cronista na voz de Maria - pensa de seu interlocutor? A imagem do Che, pelo processo polissêmico da linguagem ganhou outros (quais) significados?

Numa esfera maior, extensível o tempo todo pela infinidade de discursos que inundam a vida cotidiana, doméstica ao natural, ou em suas representações midiáticas, a rede de filiação de sentidos se altera continuamente, convocando-nos a aprender a ler o seu significado instantâneo - posto que, um segundo depois, já é outro - para sabermos se a ele reagimos com quais dizeres e não-dizeres.

Em realidade, este é o desafio que nos incita não apenas eleger em nossos estudos as teorias da comunicação, mas a agir na vida social, prática, de todo os dias.

Em Confidência do itabirano, Drummond (1977, p. 45) finaliza seu poema com esses versos sobre sua cidade natal: "Itabira é apenas uma fotografia na parede./ Mas como dói”. Para João e Maria, apesar da divergência, não doeu muito retirar a imagem do Che na parede de casa, para onde ela acabou voltando por sugestão de André. Essa imagem do "comandante", dependendo da situação discursiva, pode dizer "muito" da pessoa que a ostenta. Mas, também, pode não dizer mesmo nada. Como muitos anúncios e filmes publicitários que, em seu discurso, às vezes nada dizem mesmo sobre o produto ou serviço que divulgam. 


\section{Notas}

[1] Grifo do autor

\section{Referências}

ADORNO, Theodor W. O ensaio como forma. In: Notas de literatura. Tradução de Jorge de Almeida. São Paulo: Editora 34, 2003.

ANDRADE, Carlos Drummond de. Reunião. 10 livros de poesia. 8 ed. Rio de Janeiro: José Olympio, 1977.

BETTETINI, Gianfranco. La conversación audiovisual.Barcelona: Cátedra, 1996.

BRANDÃO, Helena Nagamine. Enunciação e construção. In. Fígaro, Roseli. Comunicação e análise do discurso. São Paulo: Contexto, 2012.

CANCLINI, Néstor García. Consumidores e cidadãos: conflitos multiculturais da globalização. Tradução de Maurício Santana Dias. 8ª ed. Rio de Janeiro: UFRJ, 2010.

CARRASCOZA, João Anzanello. Do caos à criação publicitária - Processo criativo, plágio e ready-made na publicidade. São Paulo: Saraiva, 2008.

. Razão e sensibilidade no texto publicitário. São Paulo: Saraiva, 2004.

CITELLI, Adilson. O texto astuto da publicidade. In. Carrascoza, João Anzanello. Do caos à criação publicitária - Processo criativo, plágio e ready-made na publicidade. São Paulo: Saraiva, 2008.

DOUGLAS, Mary e ISHERWOOD,Baron.O mundo dos bens:para uma antropologia do consumo. Tradução de Plínio Dentzen. Rio de Janeiro: Editora UFRJ, 2006.

ECO, Umberto. Obra aberta. Tradução de Sebastião Uchoa Leite. São Paulo: Perspectiva, 1981.

MARTÍN-BARBERO, Jesús. Dos meios às mediações - Comunicação, cultura e hegemonia. Tradução de Ronald Polito e Sérgio Alcides. 6. ed. Rio de Janeiro: UFRJ, 2009.

ORLANDI, Eni. P. Análise de discurso - Princípios e procedimentos.2 ed. Campinas: Pontes, 2000.

VERISSIMO, Luis Fernando. A mãe de Freud. Porto Alegre: L\&PM, 1985. 
Objetiva, 2013.

. Os últimos quartetos de Beethoven e outros contos. Rio de Janeiro:

WOOD, James. Como funciona a ficção. Tradução de Denise Bottmann. São Paulo: CosacNaify, 2011. 